\title{
Residual Stresses in Uniaxial Cyclic Loaded Pearlitic Lamellar Graphite Iron
}

\author{
Mattias Lundberg ${ }^{1, a, ~}{ }^{,}$, Jonas Saarimäki ${ }^{1, b}$, Ru Lin Peng ${ }^{1, ~ c}$, Johan J. Moverare ${ }^{1, d}$ \\ ${ }^{1}$ Department of Management and Engineering, Division of Engineering Materials, \\ Linköping University, SE-581 83 Linköping, Sweden \\ amattias.lundberg@liu.se, bjonas.saarimaki@liu.se, ${ }^{c}$ ru.peng@liu.se, d johan.moverare@liu.se
}

Keywords: Residual Stress, XRD, Lamellar Graphite Iron

\begin{abstract}
The mechanisms behind residual stress generation have been a topic of interest for quite some time since it is well-known that residual stresses can benefit the fatigue life of components. We have studied the residual stresses in lamellar graphite iron generated by fatigue damage. Cylindrical test specimens, with close to zero residual stresses of fully pearlitic lamellar graphite iron, manufactured and subjected to uniaxial load controlled cyclic loading, have been investigated. The load conditions used were: pure tension, pure compression, and alternating tension/compression over one thousand cycles. Measurements were performed using a four-circle goniometer Seifert X-ray machine equipped with a linear sensitive detector and a Cr-tube. Evaluation of the residual stresses were conducted using the $\sin ^{2} \psi$-method on the $\alpha$-Fe $\{211\}$ diffraction peak together with material removal technique to obtain depth profiles.
\end{abstract}

\section{Introduction}

It is well known that compressive residual stresses (RS) at the surface of a specimen prolongs the fatigue life. The associated increase in strain hardening of the surface, can be equally important for the specimen fatigue life since the combination of strain and compressive RS at the surface of the sample inhibits crack nucleation and propagation.

Steels, aluminium, titanium, and nickel alloys are some of the metallic materials in which work hardening at the surface can result in compressive RS and increased fatigue strength of the material $[1,2]$. These homogenous metallic material withstand considerable plastic deformation before final fracture compared to cast iron, especially lamellar graphite iron (LGI) which has an inhomogeneous microstructure. Lamellar graphite iron plasticises already at tensile loads $\sim 40 \mathrm{MPa}$ [3]. Graphite acts as notches all over the specimen volume and is the reason for its poor tensile strength.

Relaxation of near surface RS due to cyclic loading are a well-known phenomenon. Local plastic deformations (microcracks) as well as pinning and un-pinning of dislocations are believed to be a source of stress relaxation [2,4-6]. Residual stress relaxation mechanisms due to cyclic loading are affected by the initial magnitude of the RS, the gradient of RS, degree of cold work, cyclic loading and material response to cyclic loading [1]. In a multiphase material, such as pearlitic LGI, the different response of the phases to cyclic loading can render a measurable shift in RS in one of the phases. In this study, we have three phases (ferrite, cementite, lamellar graphite) but only the stresses in the ferritic phase, which has the largest volume fraction in the material, are measured with laboratory X-rays, since diffraction peaks for the other phases can not be obtained.

In multiphase materials, such as duplex steels, the different phases are known to have different amounts of RS and often also different signs on the stresses [7-9]. During cooling and solidification, the differences in volume contraction between phases gives a thermal mismatch, resulting in RS. The different thermal coefficients of the phases in cast iron (ferrite, cementite and graphite) are the source of RS in untreated material. Surface treatments and cyclic loading also result in plasticity mismatch between the different phases, causing large variations in RS between the phases which can also have

Content from this work may be used under the terms of the Creative Commons Attribution 3.0 license. Any further distribution of this work must maintain attribution to the author(s) and the title of the work, journal citation and DOI. Published under license by Materials Research Forum LLC. 
different signs. The effects of these RS in a LGI under cyclic loading have not been thoroughly investigated. In this paper, the RS generated in a pearlitic LGI under cyclic loading have been investigated to fill in the knowledge gap in RS progression in cast iron.

\section{Experimental setup}

Four cylindrical specimens, with a $6.3 \mathrm{~mm}$ diameter of over the $25 \mathrm{~mm}$ gauge length, of pearlitic LGI were manufactured. The specimens were manually ground using 2400 and 4000 grit $\mathrm{SiC}$ paper to lower the machining effects. Afterwards, the specimens were stress relieve annealed at $600{ }^{\circ} \mathrm{C}$ for one hour and cooled slowly in air to room temperature. Surface oxides were gently removed manually with 4000 grit $\mathrm{SiC}$ paper. The gauge length was electrolytic polished in A2-solution to achieve a stress free surface.

Uniaxial testing was performed on three test samples in an Intron 8801 servo hydraulic test machine. The fourth sample was used as reference. A sinusoidal load cycle was used in pure tension (between $20 \mathrm{MPa}$ and $200 \mathrm{MPa}$ ), pure compression (between -20 MPa to -200 MPa), and alternating tension/compression ( $\pm 150 \mathrm{MPa}$, starting in tension). The material ultimate tensile strength is 250 $\mathrm{MPa}$. Each specimen was run for 1000 cycles.

X-ray measurements were performed using a four-circle goniometer Seifert X-ray machine, equipped with a linear sensitive detector and a Cr-tube. Evaluation of RS were conducted using the $\sin ^{2} \psi$-method [10] with the $\alpha$-Fe $\{211\}$ diffraction peak, at $2 \theta \approx 156.5^{\circ}$. A ø $1 \mathrm{~mm}$ collimator was used to minimize the effects of specimen curvature. Diffraction data was obtained from four different measuring points, $\mathrm{A}-\mathrm{D}, \sim 90^{\circ}$ rotation of the specimen between each point. At every depth all diffraction data was superimposed to obtain a good average value of the RS. Peak position was calculated using a double pseudo-Voigt curve fit.

Electron backscatter diffraction (EBSD) for grain size determination was performed using an OXFORD detector in a Hitatchi SU-70 field emission gun scanning electron microscope (FEGSEM). The specimen was tilted to $70^{\circ}$ with a working distance of $20 \mathrm{~mm}$, acceleration voltage of 15 $\mathrm{kV}$ and a step size of $0.75 \mu \mathrm{m}$ were used. The HKL software Channel 5 was used to evaluate the EBSD measurements. The angle mismatch between two neighbouring points of $10^{\circ}$ or higher was set as definition of a grain boundary.

\section{Results}

The biaxial stresses for the four samples were calculated from the superimposed diffraction data (SDD), results depicted in Fig. 1. No significant differences can be observed between the samples.

\section{- Reference - Tension - Compression - Tension/Compression}

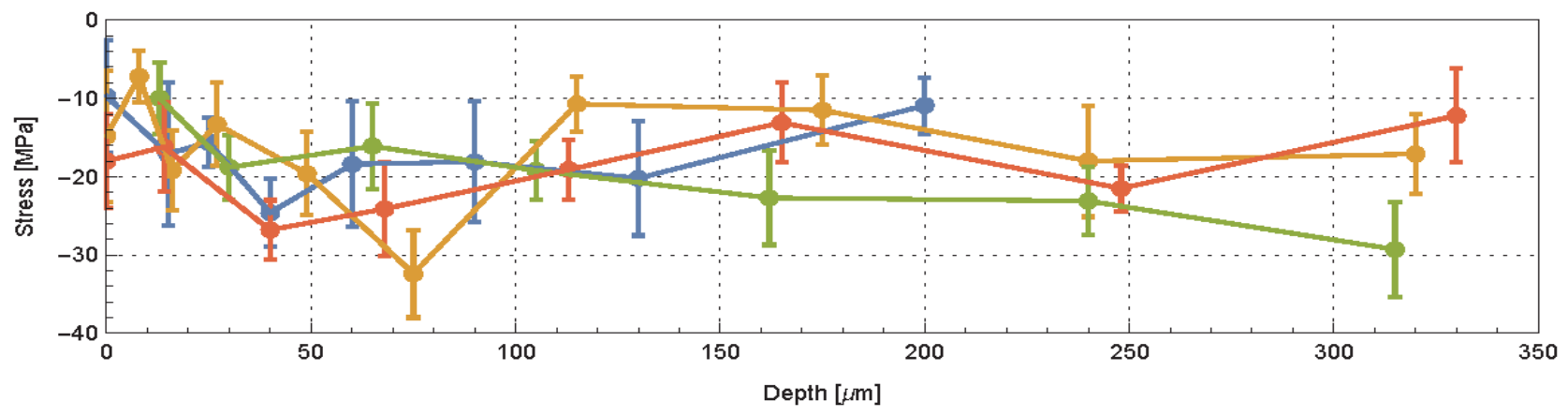

Figure 1: SDD of the four different specimens investigated.

Residual stress fluctuations and standard deviation for the reference sample are shown in Fig. 2 (a). Small tensile residual stresses for the pure tensile loaded specimen are shown in Fig. 2 (b) at some of the measured positions. The RS in the compression and tension/compression specimens in Fig. 2 (c) and (d) only show three measuring points where the RS are tensile. 
(a)

- $\mathrm{A} \cdot \mathrm{B} \cdot \mathrm{C} \cdot \mathrm{D}$
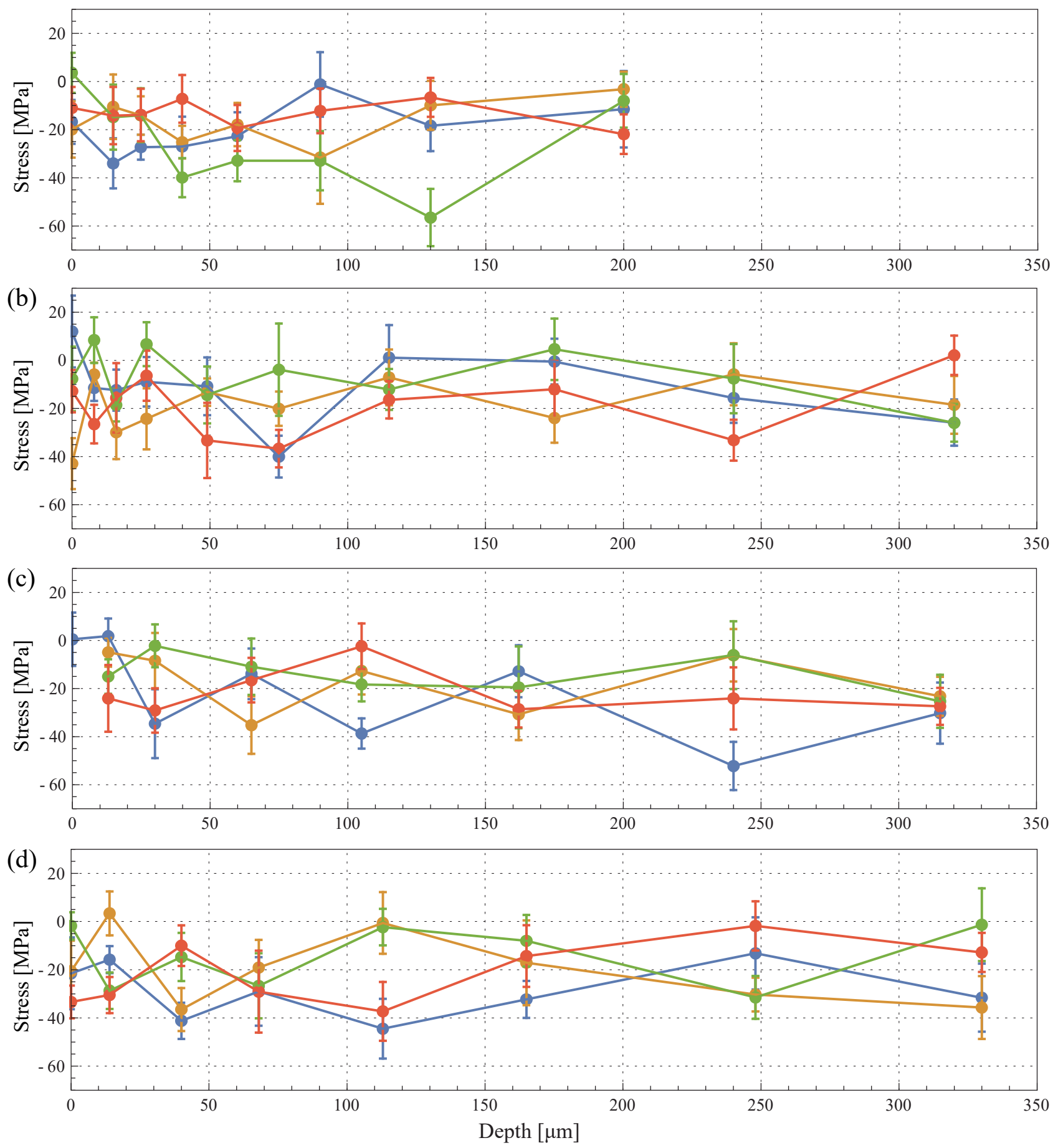

Figure 2: Residual stress profile for the four points in the (a) reference-, (b) pure tension-, (c) pure compression-, and (d) tension/compression-specimen.

All samples show an increase in Full Width at Half Maximum (FWHM) for SDD with increasing depth. No significant changes between the test specimens can be seen in Fig. 3 when comparing the average FWHM for SDD. 


\section{- Reference - Tension - Compression - Tension/Compression}

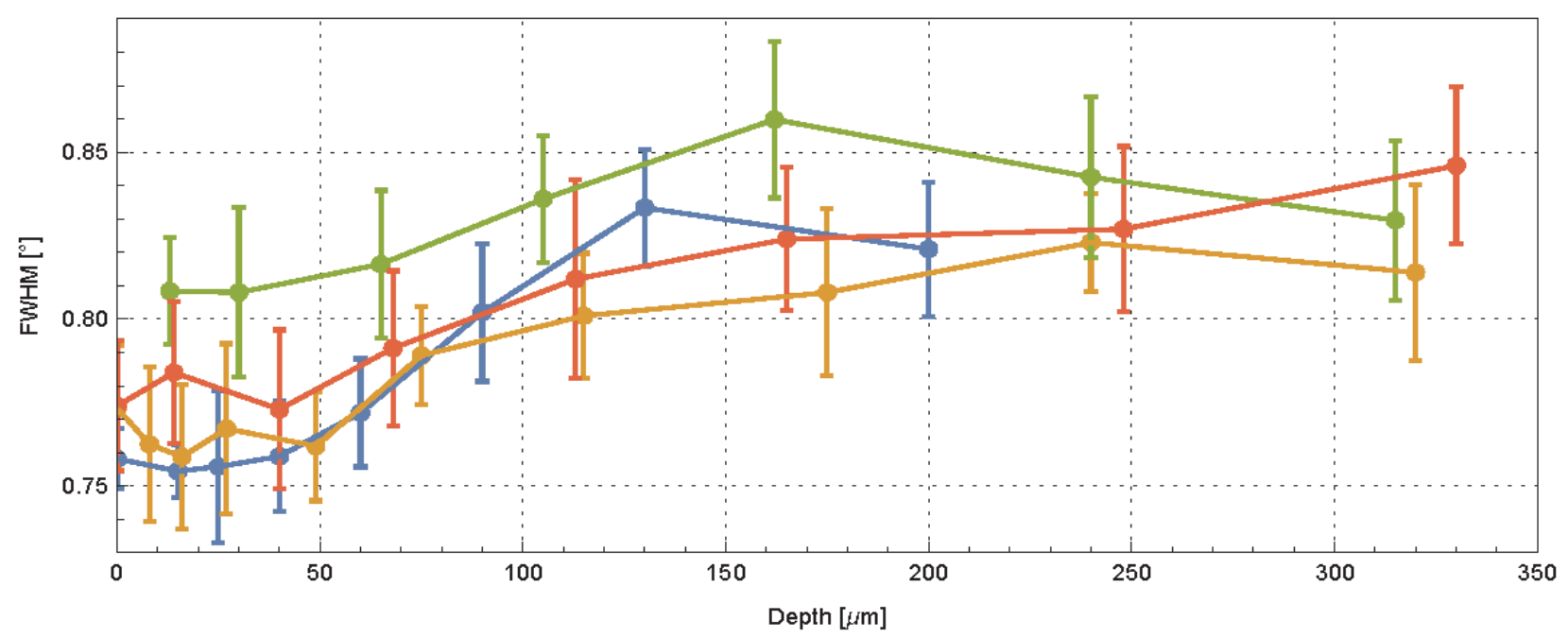

Figure 3: Averaged FWHM from SDD.

Grain size measurements conducted from EBSD-mapping of a representative area can be seen in Fig. 4. There are a few grains with a diameter larger than $200 \mu \mathrm{m}$ and a fairly even distribution of grains in the range between $50-160 \mu \mathrm{m}$. Average grain size were calculated to be $100 \mu \mathrm{m}$ with a standard deviation of $35 \mu \mathrm{m}$. The grain size measurement plot includes a lot of noise which results in a vast amount of "grains" in the $2-5 \mu \mathrm{m}$ range. This noise comes from inclusions found in the matrix.

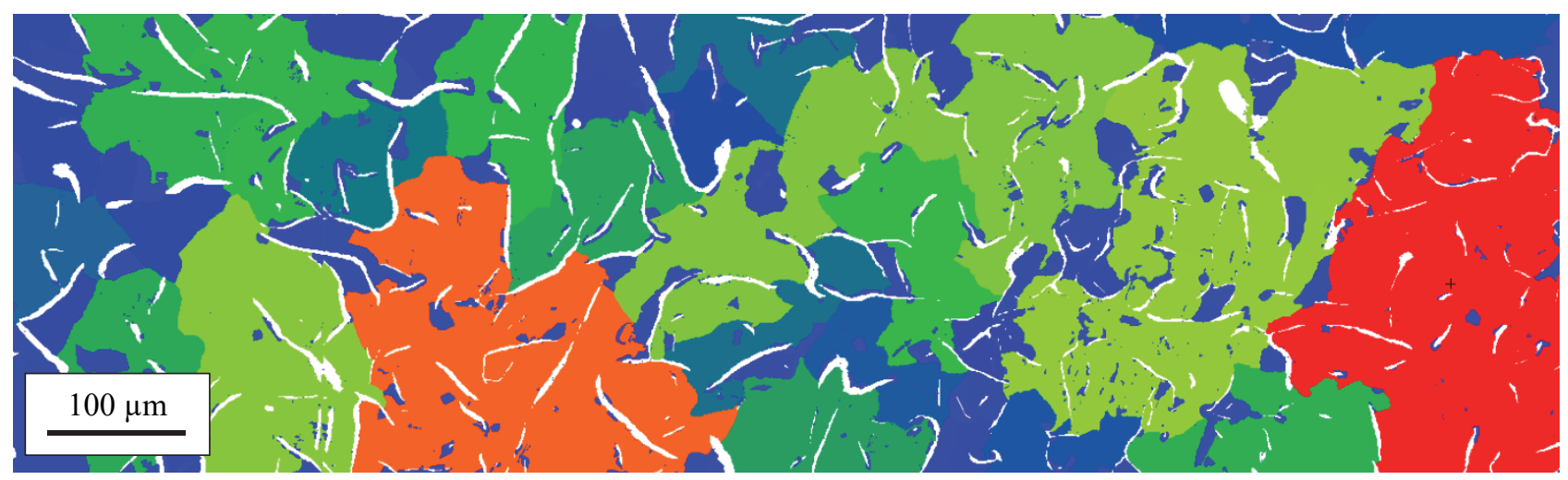

Figure 4. Grain size measurement using EBSD technique.

\section{Discussion}

Biaxial stresses for all four samples were calculated from the SDD. No significant differences can be observed between the samples. Since the accuracy of the x-ray diffraction measurements yields an uncertainty of $\pm 20 \mathrm{MPa}$ [11] as well as the overlapping standard deviations seen in Fig. 1. The reference specimen should not show any RS, nevertheless all specimens show compressive RS. To validate the accuracy of the equipment secondary reference measurements were conducted on stress free iron powder $(1.5 \pm 2.5 \mathrm{MPa})$. Since the linear fits in Fig. 5 are in the range of $-15--20 \mathrm{MPa}$ and are nearly horizontal, as well as the secondary reference measurements on stress free iron powder showed zero stresses, thermal mismatch between the phases is the most probable explanation for the measured RS. The purely compressive loaded specimen indicates an increase in compressive stress with increasing depth.

Extracting diffraction data from more than one eutectic cell in cast iron requires a large enough diffraction volume i.e., large enough collimator. Convex surfaces make the use of a large collimator inappropriate due to the curvature effect giving rise to pseudo strains [12]. Using a small collimator 
gives a small diffraction volume which can be effected by the heterogeneous strain in and around the eutectic cell structure. Fig. 2 shows the data obtained using a $\varnothing 1 \mathrm{~mm}$ collimator measuring four points evenly distributed around the cylindrical test specimen, thus resulting in diffraction data from

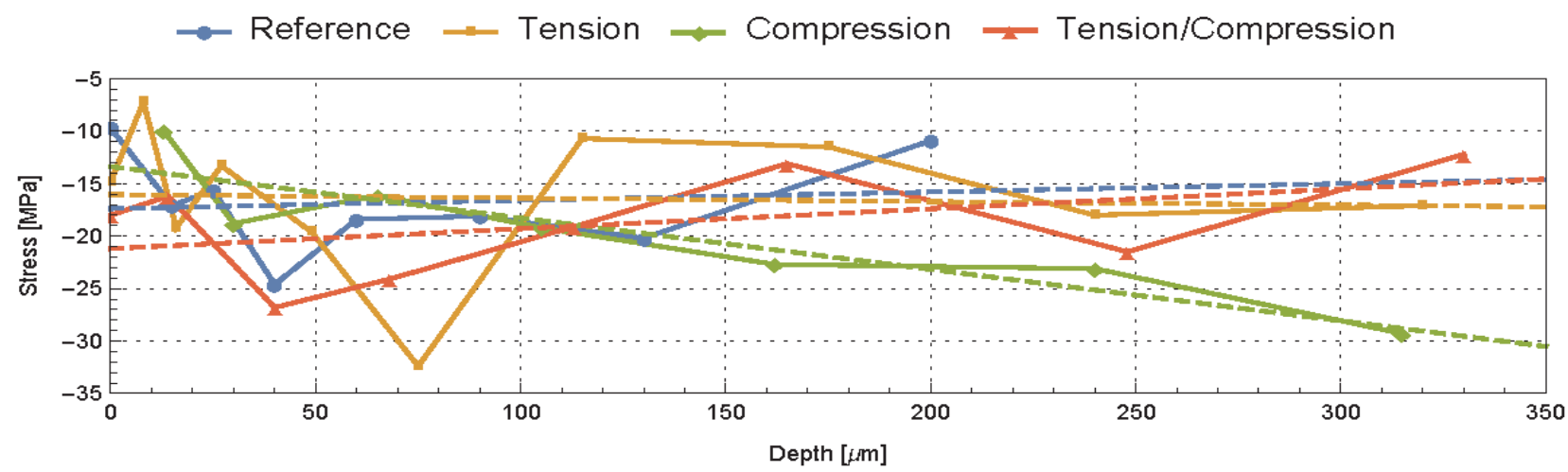

more than four eutectic cells. Superimposed diffraction data can be used to increase the statistics and to obtain the average RS in- and outside of the eutectic cells, seen in Fig. 1.

Figure 5. Linear fits showing the change of $R S$ with depth from SDD.

From the EBSD-mapping and the corresponding grain size measurement, the average grain size of $100 \mu \mathrm{m}$ results in more than the 50 individual grains within the diffraction volume needed to obtain good RS measurements. Fluctuations seen in Fig. 2 are most likely caused by thermal mismatch between the phases and the complex nature of the materials solidification since more than 50 individual grains are within the diffraction volume for every measurement, position A-D.

The FMHW distribution at each position A-D and corresponding depth varies non-conventionally and the averaged FWHM data varied between the points A-D. The averaged FWHM from SDD in Fig. 3 is therefore used to illustrate FWHM behaviour. All specimens show an increase in FWHM with depth as a result of incomplete stress relieve annealing or compositional gradient. A slightly higher dislocation density is most likely the cause of the higher FWHM values exhibited by the pure compression specimen.

The material will be strained under the influence of a mechanical load. The different macroscopic behaviour of LGI under tension and compression is related to its lamellar graphite showing notch effect under tension. If the load distribution over the whole cross-section is uniform and there is no surface effect, little RS would be expected after a low plastic loading either in compression or tension. The lower yield strength of the ferrite than the cementite can generate detectable RS under a certain degree of plastic deformation. RS will be different depending on the loading mode given that the effect of machine hardening had been removed and the specimen was stress relieve annealed. However, only a small intimation of the pure compression specimen can be seen in Fig. 5. The lack of this intimation for the other specimens is presumably due to stress relaxation mechanisms. It is well known that stress relaxation mainly occurs during the first cycles. One thousand cycles were applied to ensure a more homogenous strain field in the specimen, because of the anisotropic behaviour of the different phases. Due to the stress relaxation mechanisms, implementing one to three cycles would probably be more suited to detect large RS differences. Stress relaxation and its effects on fatigue life in cast iron need to be further investigated.

\section{Conclusions}

In this paper, the residual stresses in a pearlitic lamellar graphite iron after cyclic loading have been investigated to better understand the role of the different phases and their load capacity under influence of loadings. Four cylindrical test specimen of fully pearlitic lamellar graphite iron were normalized followed by testing and residual stress measurement conducted with laboratory X-rays. 
- There are no significant changes between the reference, pure tension, pure compression, and alternating tension/compression specimens in stresses or FWHM.

- Superimposed diffraction data (SDD) gives a more reliable result.

- Due to the stress relaxation mechanisms, implementing one to three cycles would likely be more suited to detect large residual stress differences.

\section{Acknowledgments}

Agora Materiae and AFM Strategic Faculty Grant SFO-MAT-LiU\#2009-00971 at Linköping University are acknowledged. Scania CV AB for the material and Viktor Norman for operational help with the MTS machine.

\section{References}

[1] H. Wohlfahrt, Shot peening and residual stresses, in: Sagamore Army Mater. Res. Conf. Proc., 1981: pp. 71-92.

[2] I. Nikitin, M. Besel, Correlation between residual stress and plastic strain amplitude during low cycle fatigue of mechanically surface treated austenitic stainless steel AISI 304 and ferritic-pearlitic steel SAE 1045, Mater. Sci. Eng. A. 491 (2008) 297-303.

http://dx.doi.org/10.1016/j.msea.2008.03.034

[3] M. Lundberg, M. Calmunger, R.L. Peng, In-situ SEM / EBSD Study of Deformation and Fracture Behaviour of Flake Cast Iron, in: 13th Int. Conf. Fract., 2013: pp. S12-038.

[4] W.Z. Zhuang, G.R. Halford, Investigation of residual stress relaxation under cyclic load, Int. J. Fatigue. 23, Supple (2001) 31-37.

http://dx.doi.org/10.1016/S0142-1123(01)00132-3

[5] J.D. Almer, J.B. Cohen, B. Moran, The effects of residual macrostresses and microstresses on fatigue crack initiation, Mater. Sci. Eng. A. 284 (2000) 268-279.

http://dx.doi.org/10.1016/S0921-5093(99)00779-0

[6] K. Zhan, C.H. Jiang, V. Ji, Residual Stress Relaxation of Shot Peened Deformation Surface Layer on S30432 Austenite Steel under Applied Loading, Mater. Trans. 53 (2012) 1578-1581. http://dx.doi.org/10.2320/matertrans.M2012111

[7] N. Jia, R.L. Peng, Y.D. Wang, G.C. Chai, S. Johansson, G. Wang, P.K. Liaw, Interactions between the phase stress and the grain-orientation-dependent stress in duplex stainless steel during deformation, Acta Mater. 54 (2006) 3907-3916.

http://dx.doi.org/10.1016/j.actamat.2006.04.019

[8] M.L. Martinez-Perez, F.J. Mompean, J. Ruiz-Hervias, C.R. Borlado, J.M. Atienza, M. GarciaHernandez, M. Elices, J. Gil-Sevillano, R.L. Peng, T. Buslaps, Residual stress profiling in the ferrite and cementite phases of cold-drawn steel rods by synchrotron X-ray and neutron diffraction, Acta Mater. 52 (2004) 5303-5313.

http://dx.doi.org/10.1016/j.actamat.2004.07.036

[9] J.J. Moverare, M. Odén, Deformation behaviour of a prestrained duplex stainless steel, Mater. Sci. Eng. A. 337 (2002) 25-38.

http://dx.doi.org/10.1016/S0921-5093(02)00022-9

[10] I.C. Noyan, J.B. Cohan, Residual stress - Measurement by Diffraction and Interpretation, 1987.

[11] P.J. Withers, H.K.D.H. Bhadeshia, Residual stress. Part 1-measurement techniques, Mater. Sci. Technol. 17 (2001) 355-365.

http://dx.doi.org/10.1179/026708301101509980

[12] I.C. Noyan, J.B. Cohan, Residual stress - Measurement by Diffraction and Interpretation, 1987. 